\title{
Designing a model for promoting the participation of men in sexual and reproductive health using Structural Equation Modeling-Partial Least Squares (SEM-PLS)
}

\author{
Ziba Taghizadeh${ }^{1}$, Hamid Ravaghi², Nasrin Sarafraz ${ }^{3}$, Nahid Jafari ${ }^{4}$, Mahshid Taheri ${ }^{3}$
}

\begin{abstract}
Background and purpose of the study: Undoubtedly, without sexual and reproductive health, women will not be able to achieve their other rights. This goal will be achieved only when they are supported by men. Therefore, the present study was conducted with the aim of providing information required to design a model for promoting the men`s participation in sexual and reproductive health using structural equation modeling-partial least squares.

Methodology: This research was a descriptive-analytical study conducted on 150 married men who were randomly included in the study. The data collection tool was a researcher-made questionnaire designed based on the results of a qualitative study and a review of articles. Its validity and reliability have been already examined. Data were collected through a questionnaire and analyzed by structural equation modeling.

Results: The results of this study revealed that all strategies for the promotion of men's participation, except for the solution of "maximum use of religious capacities", had a normal distribution, and according to the positive values of the CV-Redundancy Index and the CV - Communality Index, the structural model had a good and appropriate fit for all variables.

Conclusion: According to the results, the high-level decision-makers can be informed to decide where and how to focus their efforts and resources so that they can maximize the participation of men in sexual and reproductive health.
\end{abstract}

Keywords: promoting men's participation, sexual and reproductive health, structural equations

\section{INTRODUCTION}

The importance of women's health and its effect on the family and the community is clear for everyone. Without sexual and reproductive health, women will not be able to achieve their other rights. However, the health right, especially women's sexual and reproductive right, is not yet achieved in many parts of the world. According to published statistics on the burden of diseases, 22 percent of the lost lives in women of reproductive age are due to ignoring sexual and reproductive health rights and related problems such as unplanned pregnancy, maternal morbidity and mortality, sexually transmitted diseases and AIDS, while sexual and reproductive health problems account for only $3 \%$ of the disease burden of men of reproductive age (1).

Biological factors alone do not justify this inequality of the burden of disease in both genders, but social, economic, and policy deficiencies have a harmful effect on women's reproductive health (2-6). The reproductive health is dealing with the health of the mother, the fetus and the father directly and simultaneously. Each of these three components has different effects on each other. Therefore, the issue of "reproductive health" is not exclusive to women. Although women's health is its main axis, it includes the policies on the participation of men in reproductive health to some extent (7), as reproductive health was replaced by family planning since 1994 and the role and status of men was one of its

\footnotetext{
1 Nursing and Midwifery Care Research Center, Tehran University of Medical Sciences, Tehran, Iran.

2 Department of Health Services Management, School of Health Management and Information Sciences, Iran University of Medical Sciences, Tehran, Iran.

3 Department of Reproductive Health, School of Nursing and Midwifery, Tehran University of Medical Sciences, Tehran, Iran.

${ }^{4}$ Assistant Professor of Community Medicine Vice Chancellery for HealthIran

Ministry of Health and Medical Education, Tehran, Iran.
}

\author{
Correspondence: Nasrin Sarafraz \\ Department of Reproductive Health, School of Nursing and Midwifery, Tehran \\ University of Medical Sciences, Tehran, Iran. \\ E-mail: sarafraz1385@gmail.com
}

Received: 15 Jul 2019, Accepted: 29 Nov 2019

(C) 2019 by the authors; licensee Modestum Ltd., UK. This article is an open access article distributed under the terms and conditions of the Creative Commons Attribution License (http://creativecommons.org/licenses/by/4.0/). 
aspects (8). The role of men in reproductive health varies. It includes a partner for women, spouse, father, family head, leadership in the community, and generally being involved in the economy, information, politics and programs. Therefore, the success of sexual and reproductive health programs depends on the attitude and performance of men (8).

The results of a research conducted by Afshani et al. (2008) showed that the role of men in health and reproductive control based on the theories of dissemination and economic theories in the reproductive area was very important, so that the level of modernity, the level of income and their educational level were associated with their health and reproductive control (9). Accordingly, when men do not pay attention to sexual and reproductive health issues at decision-making, occupational and family life levels for cultural, social and economic reasons, the dimensions of the current problems of women of reproductive ages increases dramatically. In addition, poor educational performance and low knowledge of men about the needs and issues of pregnancy are another factor that reduces men's participation in sexual and reproductive health programs. Mortazavi and Mirzaei (2012) showed that the high level of men's knowledge of their spouse problems and accompanying them to receive pregnancy care is a sign of the interest of men in reproductive health, but low knowledge of men about the needs of pregnant women and pregnancy problems are important barriers for men's supportive behaviors (10).

In this regard, Cappiello et al. (2017) showed that educational courses of sexual and reproductive health should be in priority of curricula and educational programs (11). Shahjahan et al. (2013) introduced the effective factors on men's participation in reproductive health as higher levels of education, number of children, income, employment status, duration of marriage and access to media (12). Onyango et al. (2010) also showed that gender norms, negative cultural performance, and indifference of policy makers to these norms are among the most important factors affecting men's participation in sexual and reproductive health (13). In general, the results of this study suggested that men's participation in sexual and reproductive health programs is a multifactorial phenomenon. These factors include a set of cultural, social, family, political, economic and educational causes.

Given what was stated above and the importance of men in sexual and reproductive health, designing an applied model with the aim of developing and improving men's participation in sexual and reproductive health program is necessary. Therefore, this study was conducted with the aim of designing a model for promoting men's participation in the sexual and reproductive health of their spouses (36-38).

\section{MATERIALS AND METHODS}

This research was a descriptive-analytical study conducted with the aim of determining the normal distribution of the strategies to promote the men's participation and design a model in this regard. The research population included all married men. The required sample size was estimated to be 150 people according to the objectives of the design, type and method of the study and using the previous studies with an effect size of E.S $=20 \%$ with a power of $80 \%$ and a $95 \%$ confidence and

$$
n^{\prime}=\frac{\left(z_{1-\frac{\alpha}{2}}+z_{1-\beta}\right)^{2}}{\left(\frac{d}{2 \delta}\right)^{2}}
$$

using the formula of the data collection tool was a questionnaire with 12 strategies for promoting men's participation in reproductive and sexual health. It was designed based on the results of a qualitative study and a review of the articles. The validity of the questionnaire was also examined using two convergent and divergent criteria that are specific to structural equations modeling.

Convergent validity refers to the ability of indicators of one dimension to explain that dimension and divergent validity implies that the research model structures should be more correlated with their own questions than the other structures (14). In this stage, the average of the variance extracted (AVE) criterion was used to assess the convergent validity $(39,40)$. The criterion value to accept it, was 0.4 (14). In this study, as shown in Table 1, the AVE values for all structures of the questionnaire were higher than the standard 0.4 , indicating that it was an acceptable value for the convergent validity of the tool for measuring these structures (41).

In order to calculate the divergent validity, the correlation of each model structure with its own versus correlation with other structure of the model was examined. It was performed by comparing the AVE of each structure (values substituted in the diameter of the matrix) with the values of the correlation coefficient between the structures. As the results of this study showed, since the correlation coefficients of each structure with the structure itself were more than 
Table 1: Average of variance extracted (AVE) for questionnaire structures (convergent validity)

\begin{tabular}{lccccc}
\hline & $\begin{array}{c}\text { Reforming and } \\
\text { promoting } \\
\text { educational systems }\end{array}$ & $\begin{array}{c}\text { Adopting } \\
\text { appropriate health } \\
\text { system policies }\end{array}$ & $\begin{array}{c}\text { Government } \\
\text { support }\end{array}$ & $\begin{array}{c}\text { Socio-cultural } \\
\text { policies }\end{array}$ & $\begin{array}{c}\text { Promotion of men's } \\
\text { participation in reproductive } \\
\text { and sexual health }\end{array}$ \\
\hline $\begin{array}{l}\text { Average of variance } \\
\text { extracted (AVE) }\end{array}$ & 0.56 & 0.65 & 0.71 & 0.72 & 0.80 \\
\hline
\end{tabular}

Table 2: Matrix of squared AVE and correlation coefficients of the questionnaire structures (divergent validity)

\begin{tabular}{|c|c|c|c|c|c|}
\hline & $\begin{array}{c}\text { Reforming and } \\
\text { promoting } \\
\text { educational system }\end{array}$ & $\begin{array}{c}\text { Adopting } \\
\text { appropriate health } \\
\text { system policies }\end{array}$ & $\begin{array}{l}\text { Government } \\
\text { support }\end{array}$ & $\begin{array}{l}\text { Socio-cultural } \\
\text { policies }\end{array}$ & $\begin{array}{l}\text { Promotion of men`s } \\
\text { participation in reproductive } \\
\text { and sexual health }\end{array}$ \\
\hline $\begin{array}{l}\text { Reforming and promoting } \\
\text { educational system }\end{array}$ & 0.748 & & & & \\
\hline $\begin{array}{l}\text { Adopting appropriate health } \\
\text { system policies }\end{array}$ & 0.591 & 0.806 & & & \\
\hline Government support & 0.7 & 0.531 & 0.842 & & \\
\hline Socio-cultural policies & 0.667 & 0.461 & 0.679 & 0.848 & \\
\hline $\begin{array}{l}\text { Promotion of men's } \\
\text { participation in reproductive } \\
\text { and sexual health }\end{array}$ & 0.889 & 0.757 & 0.872 & 0.833 & 0.894 \\
\hline
\end{tabular}

Table 3: Calculation of Cronbach's Alpha and Composite Reliability for research tool measuring the structures

\begin{tabular}{lcc}
\hline & (Cronbach's Alpha) & (Composite Reliability) \\
\hline Reforming and promoting educational system & 0.74 & 0.83 \\
\hline Adopting appropriate health system policies & 0.74 & 0.85 \\
\hline Reforming and promoting educational system & 0.61 & 0.83 \\
\hline Socio-cultural policies & 0.81 & 0.88 \\
\hline Promotion of men's participation in reproductive and sexual health & 0.85 & 0.90 \\
\hline
\end{tabular}

the correlation coefficient of the structures with each other, the divergent validity of the model was confirmed. The results of this study are shown in Table $\mathbf{2}$. In order to evaluate the reliability of the questionnaire, "partial least squares (PLS)" method was used.

In partial least squares method, reliability was measured by two criteria: 1) Cronbach's alpha and 2) composite reliability (CR). In fact, the Cronbach's alpha coefficient indicates the ability of questions to explain their dimensions accurately. In addition, composite reliability determines the level of correlation between the questions of one component (15). In general, the Cronbach's alpha and the composite reliability coefficient above 0.6 represent an acceptable reliability of measurement tools (15). In this study, the Cronbach's alpha coefficients and composite reliability for all structures were more than the standard value of 0.6 , which indicated the reliability of the tool for measuring this structure. Table 3 shows the results of these investigations.

To determine the normal distribution of strategies for promoting men's participation in reproductive and sexual health areas, SPSS version 20 software and one-sample T test were used. Moreover, using the Smart-PLS Structural Equation Modeling Software, the proposed model was designed to promote men's participation in the reproductive and sexual health area, and its qualitative fit was calculated (42).

\section{RESULTS}

The results of this study showed that all strategies for promoting men's participation, except for "maximum use of religious capacities", had normal distribution. Table 4 shows the results of this investigation.

After calculating the normal distribution of strategies, the model of promotion of men's participation in reproductive and sexual health was designed using the structural equation model with the help of Smart PLS software, and the observed and latent variables of the model were identified. In addition, in this study, path coefficients and factor loads to determine the direction of the effect of latent independent variables of the model (reforming and promoting educational systems, adopting appropriate health system policies, government support, and socio-cultural policies) on the latent dependent variable of the model "men's participation in the reproductive and sexual health "was calculated. As the results of the model show, the variance explained by the latent variable of men's participation in the reproductive and sexual health was explained by latent independent variables by 0.999 . The path coefficients was 0.325 for the variable 
Table 4: One-sample t-test for the calculation of the normal distribution of strategies for promoting men 's participation in the reproductive and sexual health area

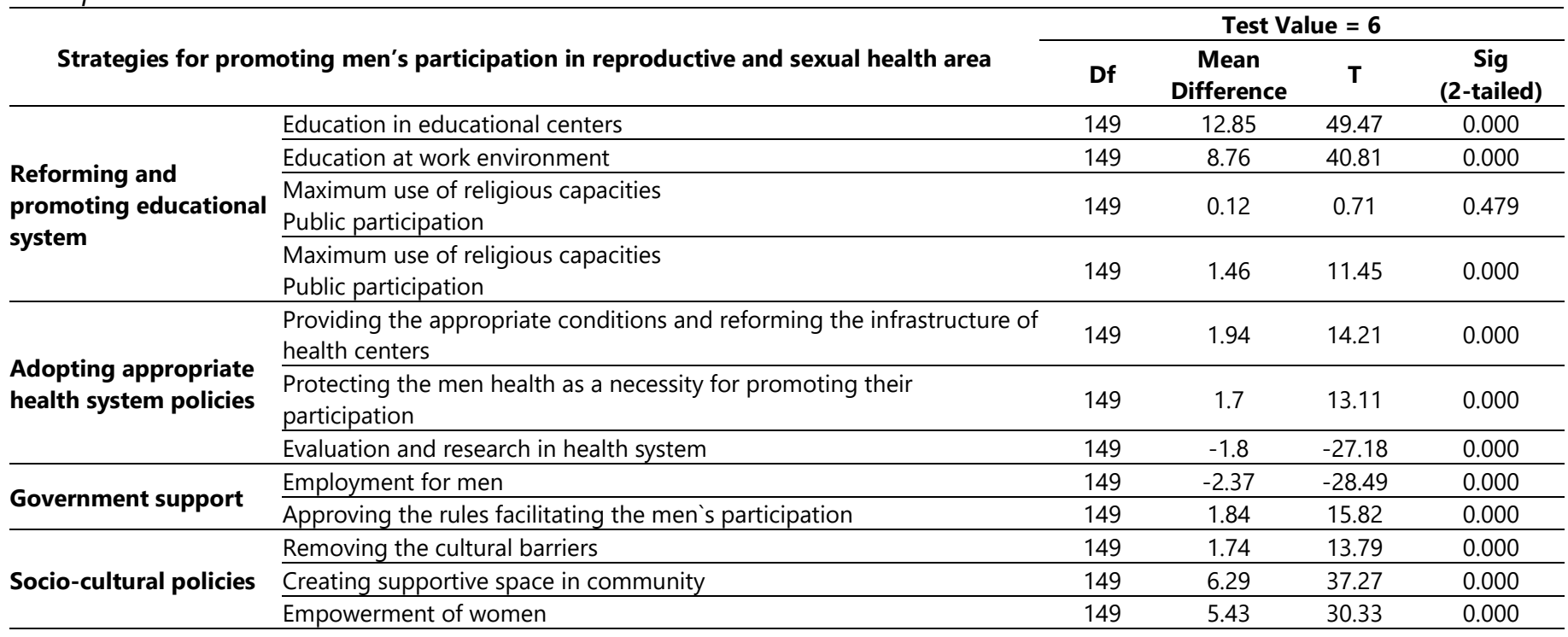

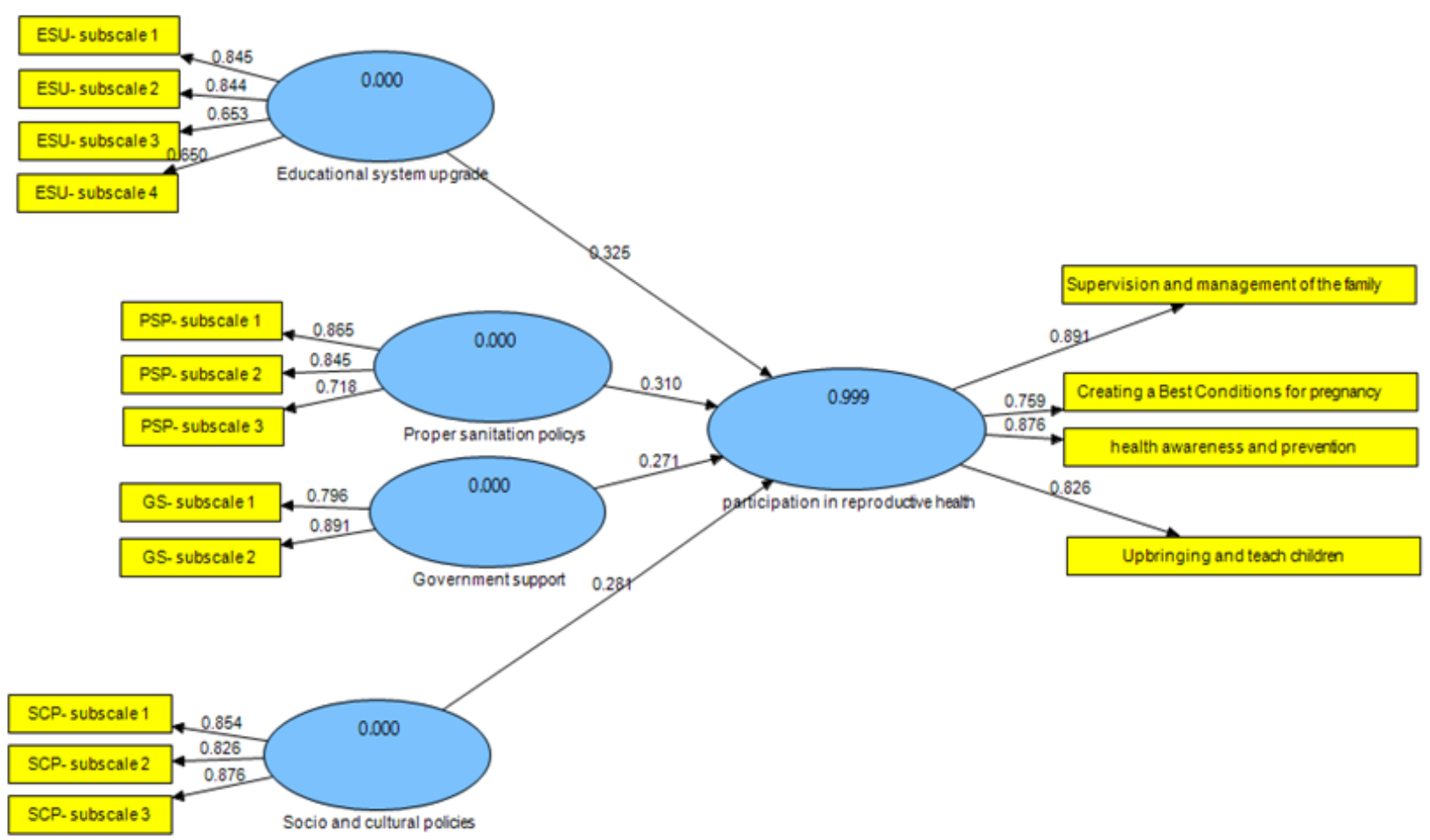

Figure 1: Proposed model for promoting men`s participation in reproductive and sexual health

of reforming and promoting the educational systems, 0.310 for adopting appropriate health system policies", 0.271 for government support and 0.281 for social-cultural policies.

The factor load of the observed variables and their indirect effect on each other was also calculated in this study. Additionally, the significance of path coefficients and factor loads of the model was calculated. The results of this investigation showed that the $t$ values of the path lines and the lines related to the factor loads between the model variables were more than the standard value of 2.58, so they were significant at the level of 0.01 . Figures 1 and $\mathbf{2}$ show the proposed model for promoting men's participation in the reproductive and sexual health area and its significance.

The results of examining the model quality showed that according to the positive values of the CV-Redundancy index and the CV-Communality index, the structural model for all variables had a good quality and significant fit. Figure 3 shows the results of the quality and significance fit of the model. 


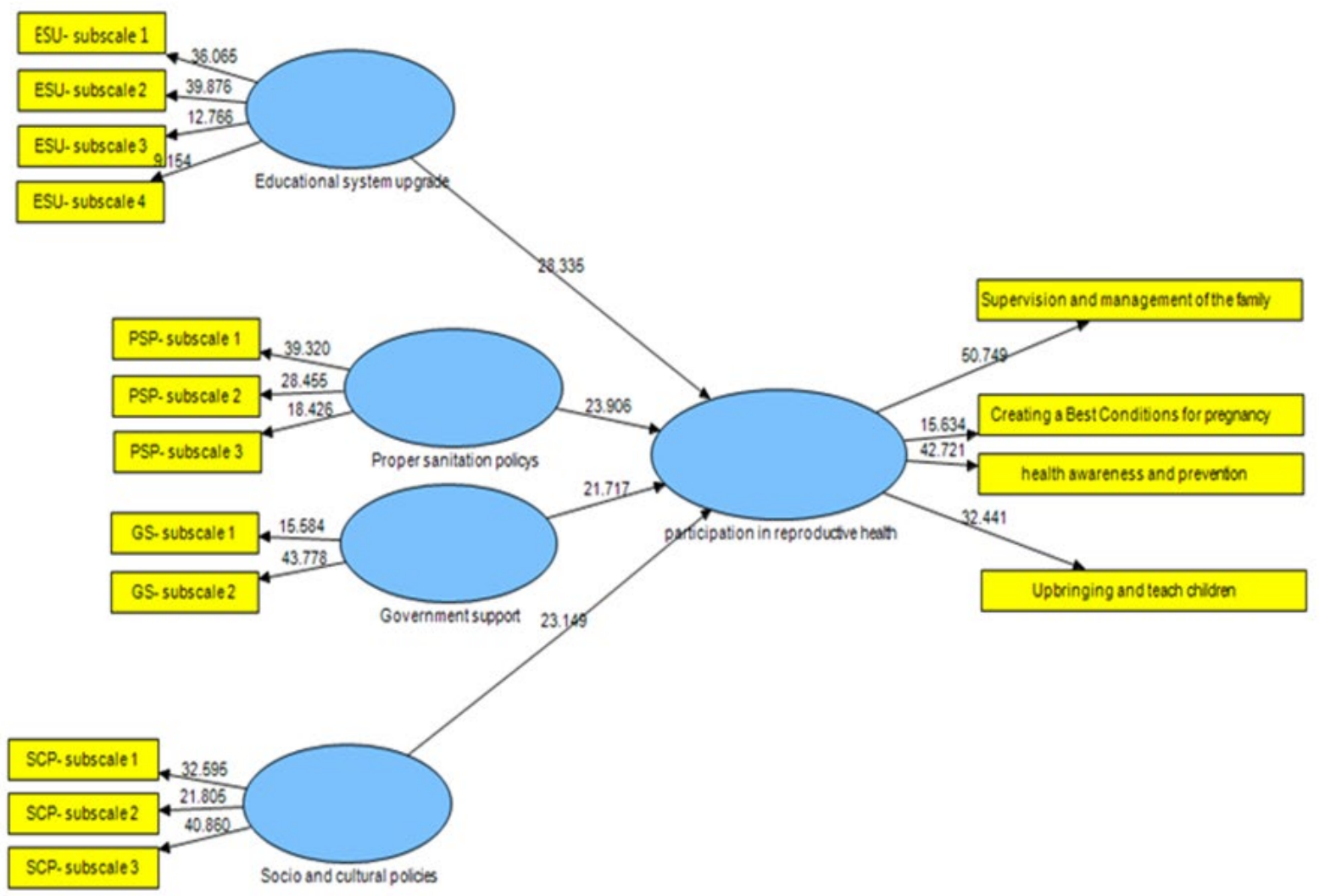

Figure 2: Calculation of the significance of path coefficients and factor loads of the model of promoting male participation in the reproductive and sexual health area

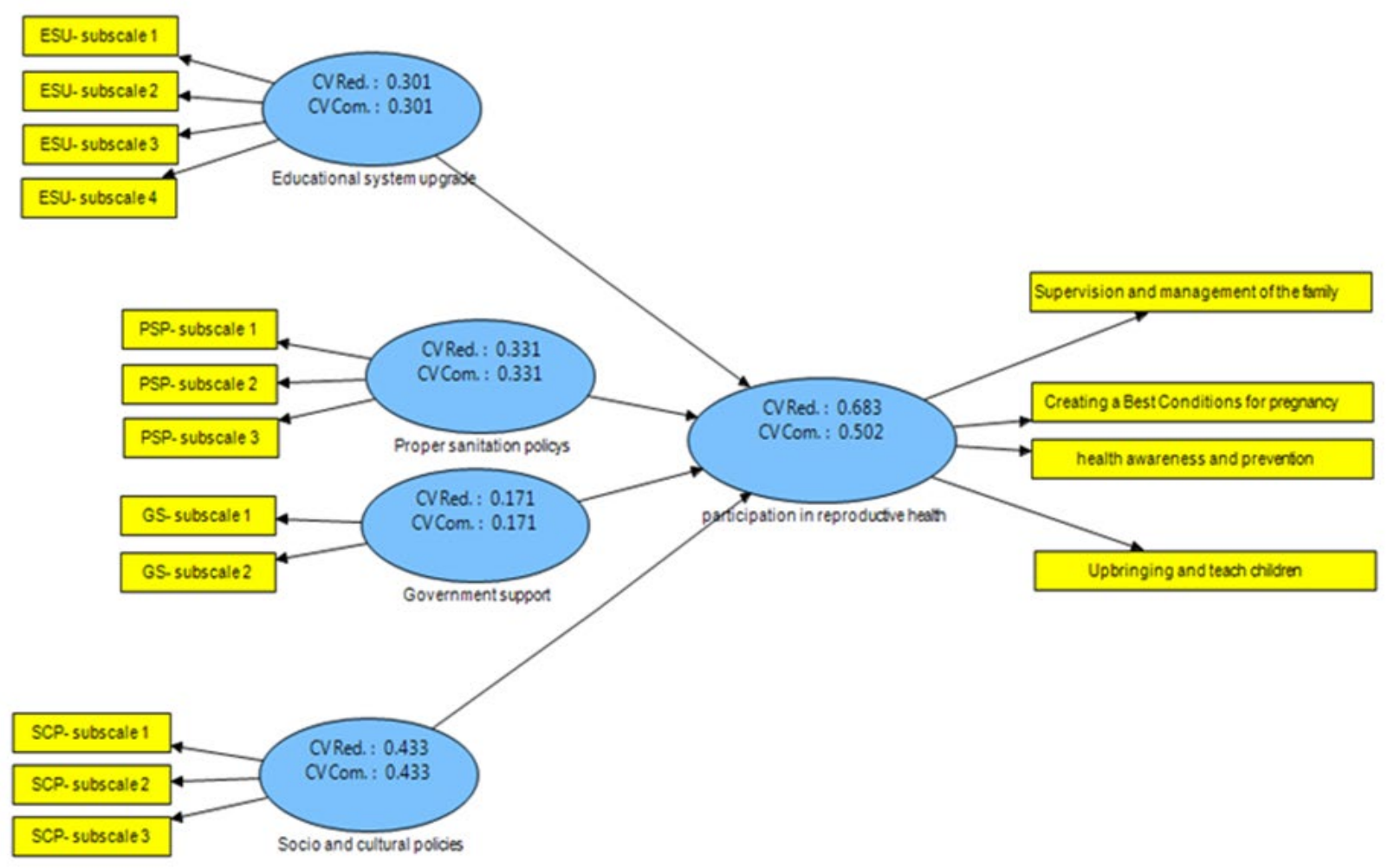

Figure 3: The results of the quality and significance fit of the model 


\section{DISCUSSION}

Given what was stated in this study, we can provide the conditions for better male participation in sexual and reproductive health by reforming the educational systems. These results were in line with the results of other studies in the area of educating the men's participation skills in sexual and reproductive health $(7,8,11,16-19)$. In explaining this result, it can be said that the establishment of such an educational system will ensure that men acquire the skills necessary for the sexual and reproductive health and can make an effort to protect the health of the mother and the child by appropriate mechanisms. Additionally, men gain many profits by reforming educational programs. Some of these benefits include gaining knowledge on women's behavior and feelings during pregnancy and communication sensitivities of this period, increasing knowledge of pregnancy, identifying future health needs, identifying experiential and educational requirements for marital relationships, and identification of educational needs that lead to better quality and better health of their marital relationships. Moreover, the results of this study were in line with the results of the study conducted by Conen et al. (19) as it emphasized that providing education to men would lead to an improved relationship between a man and his wife and it would lead to increased care of sexually transmitted infections, sexual intercourse, immunization, and so on.

With regard to "adopting appropriate health system policies", the results of this research showed that using three categories of providing appropriate conditions and infrastructure for health centers, protecting the health of men as a necessity for promoting their participation and evaluating and researching in the health system, it is possible to increase the men's participation in sexual and reproductive health. This result was consistent with that of research conducted by Mortazavi and Mirzaei (10), Molani (20), Occhico et al. (21), and Mortazavi (22). In explaining this result, as Mortazavi reported with regard to the impact of health infrastructure such as shortage of manpower, shortage of space on the lack of participation of men in sexual and reproductive health centers $(10,22)$ and with regard to the importance of mental and physical health of men as a requirement for participation in sexual and reproductive health (23-26) and given the importance of conducting comprehensive research on the sexual and reproductive health in the health system $(7,27)$, it can be stated that the adoption of new and effective health policies in the areas of developing physical infrastructure, scientific and research infrastructure, and focusing on protecting the general health of men are effective steps to promote men's participation in sexual and reproductive health. Hence, reforming health policies, such as infrastructure development and increasing opportunities is expected to be a driving force to increase the men 's participation in sexual and reproductive health.

With regard to the theme of "government support," the results of this study showed that using the two categories of job creation for men and approving the rules to facilitate men 's participation could provide the conditions for continued participation of men in sexual and reproductive health. This result was consistent with other research results (9-29,2128,30). The results of this study suggested that governments can motivate men to participate in sexual and reproductive health with a variety of public policies, such as regulatory and distributional policies in the area of improving the economic status and income levels as well as approving the rules and regulations in the health sector (43). In fact, the health system consists of components that are related to each other and their composition affects the health of the people. In this regard, government is one of the essential components playing key role in the community health (31), so that there is a positive relationship between public policies and the quality of government policies and between democracy and indicators and outcomes of health policies (32). Hence, it is expected that government can increase the men's participation in sexual and reproductive health with its appropriate and timely policies. Therefore, it is essential that the government provide job and financial security for men by creating job for them in order to develop the health programs related to men's participation in sexual and reproductive health. It is also expected that government can take steps to facilitate and implement the designed programs for men's participation in sexual and reproductive health by the rules passed by Health Ministry.

With regard to the theme of "social-cultural policies", the results of this study showed that using the three categories of removing men cultural barriers, creating a supportive space in society, and empowerment of women, it is possible to enhance the men's participation in sexual and reproductive health. This result was consistent with that of other studies $(10,13,18,22,33)$. The results of this study suggested that reproductive health is an issue with high cultural and social sensitivity and any policy and planning for the participation of men in the sexual and reproductive health requires paying attention to cultural and social characteristics of the target groups. In fact, none of the health programs related to men's participation in the sexual and reproductive health will be realized without considering the socio-cultural context conditions and without providing the appropriate cultural conditions. Therefore, it can be stated that the cultural priorities and social factors direct the strategies of men`s participation in sexual and reproductive health. In general, the 
results of structural equation analysis showed that the model presented in this study had a significant and acceptable fit (47). The results of this analysis showed that among all identified dimensions or themes, reforming educational systems, adoption of appropriate health system policies, government support, and socio-cultural policies had a significant and strong relationship with the participation of men in sexual and reproductive health. These results, consistent with other results of other studies $(7,10,12,13,18,19,21,22,33,34)$, showed that it is possible to promote men's participation in sexual and reproductive health using an integrated designed program, focusing on reforming the educational systems, adopting appropriate health system policies, government support, and socio-cultural policies (44). Therefore, it is expected that the model presented in this study can enhance men's participation in sexual and reproductive health areas including the participation of men in providing safe cares for mothers, prevention of violence against women, counseling on the formation of high-risk sexual behaviors, education on gender equality, protecting the reproductive health of self and spouse, and so on (45).

\section{CONCLUSION}

According to the results of this study, it is expected to inform those who are responsible for reproductive health policy-making in order to make appropriate decisions in their programs that help to eliminate the barriers of men's participation in reproductive health. It also informs the high-level decision makers to decide how and where to focus their efforts and resources so that they can maximize the participation of men in the sexual and reproductive health. In addition, one of the important features of this study is its comprehensiveness as it considers all dimensions and components related to men's participation in reproductive health, increasing the possibility of integrating the designed model in the health system of Iran.

\section{ETHICAL CONSIDERATIONS}

Due to high cultural sensitivity of the sexual and reproductive health issue in the studied population, informed consent was taken from all participants and they were ensured that their personal information would remain confidential. In addition, the permission to conduct this research was obtained by Ethics Committee of the University under the code of IR.Tums.VCR.1395.1044.

\section{ACKNOWLEDGEMENT}

Authors of this article appreciate Research Deputy of Tehran University of Medical Sciences and Health Services as well as all those who participated in this study.

\section{REFERENCES}

1. AbouZahr C, Vaughan JP. Assessing the burden of sexual and reproductive ill-health: questions regarding the use of disability-adjusted life years. Bulletin of the World Health Organization, 2000;78:655-66.

2. Salehin M. Modeling Tribal Women's Reproductive Health in India: A Theoretical Perspective. Social Development Issues, 2016;38(3):1-17.

3. Glasier A, Gülmezoglu AM, Schmid GP, Moreno CG, Van Look PF. Sexual and reproductive health: a matter of life and death. The Lancet, 2006;368(9547):1595-607.

4. Browner CH, Root R. Cultural Contexts of Reproductive Health. In: Quah SR, editor. International Encyclopedia of Public Health (Second Edition). Oxford: Academic Press; 2017. p. 187-90. https://doi.org/10.1016/B978-0-12803678-5.00094-1

5. Hadi M. Historical development of the global political agenda around sexual and reproductive health and rights: A literature review. Sexual \& Reproductive Healthcare, 2017;12:64-9. https://doi.org/10.1016/j.srhc.2017.03.005 PMid:28477934

6. Coleman-Minahan K. The socio-political context of migration and reproductive health disparities: The case of early sexual initiation among Mexican-origin immigrant young women. Social science $\&$ medicine, 2017;180:8593. https://doi.org/10.1016/j.socscimed.2017.03.011 PMid:28324794 PMCid:PMC5452611

7. Alimoradi Z, Simbar M. Male Involvement in Reproductive and Sexual Health: A Systematic Review of Iranian Literature. Hakim, 2014;17(3):222-09. 
8. Niazi M, Akhavan-Akbari P. The role of men in promoting reproductive health services. In: Sciences TSCoAUoM, editor. 3th Student Congress of Ardabil University of Medical Sciences; Ardabil University of Medical Sciences Shahid Moghaddam Conference Hall. March 1, 2012.

9. Afshani S, Askarinadoshan A, Zarehshaabadi A, Fazelnajafabadi S. The role of men in family planning and fertility control in Yazd. Social Welfare Quarterly, 2008;7(27):29-51.

10. Mortazavi F, Mirzaii K. Reason of, barriers to, and outcomes of husbands' involvement in prenatal and intrapartum care program based on midwives' experiences: A qualitative study. Journal of Arak University of Medical sciences, 2012;15(1):104-15.

11. Cappiello J, Coplon L, Carpenter H. Systematic review of sexual and reproductive health care content in nursing curricula. Journal of Obstetric, Gynecologic \& Neonatal Nursing, 2017;46(5):e157-e67. https://doi.org/10.1016/j.jogn.2017.04.132 PMid:28654768

12. Shahjahan M, Mumu SJ, Afroz A, Chowdhury HA, Kabir R, Ahmed K. Determinants of male participation in reproductive healthcare services: a cross-sectional study. Reproductive health, 2013;10(1):27. https://doi.org/10.1186/1742-4755-10-27 PMid:23680449 PMCid:PMC3663737

13. Onyango MA, Owoko $S$, Oguttu M. Factors that influence male involvement in sexual and reproductive health in western Kenya: a qualitative study. African journal of reproductive health, 2010;14(4).

14. Campbell DT, Fiske DW. Convergent and discriminant validation by the multitrait-multimethod matrix. Psychological bulletin, 1959;56(2):81. https://doi.org/10.1037/h0046016

15. Peterson RA, Kim Y. On the relationship between coefficient alpha and composite reliability. Journal of Applied Psychology, 2013;98(1):194. https://doi.org/10.1037/a0030767 PMid:23127213

16. Goshtasebi A, Azin S. Sex education programs: Necessity and ethical considerations. Journal of Medical Ethics and History of Medicine, 2013;5(8):19-0.

17. Cliquet RL, Thienpont K. Population and development: A message from the Cairo conference: Springer Science \& Business Media; 2013.

18. Simbar M, Nahidi F, Ramezankhani A. Fathers' educational needs about perinatal care: A qualitative approach. Hakim Research Journal, 2009;12(2):19-31.

19. Kunene B, Beksinska M, Zondi S, Mthembu N, Mullick S. Involving men in maternity care South Africa. 2004. https://doi.org/10.31899/rh4.1204

20. Mullany BC. Barriers to and attitudes towards promoting husbands' involvement in maternal health in Katmandu, Nepal. Social science \& medicine, 2006;62(11):2798-809. https://doi.org/10.1016/j.socscimed.2005.11.013 PMid:16376007

21. Okechukwu O, Adegbenro C, Moses O, Amos O, Olanrenwaju O. Men's involvement in safe motherhood. J Turkish-Germany Gynecol Assoc. 2007;8:240Á6.

22. Mortazavi $F$, editor The study of male involvement in prenatal care in Shahrod and Sabzevar. The First International \& 4th National Congress on health Education \& Promotion, 2011. Tabtiz University of medical sciences.

23. Reddy A, Parikh MJ, Gabrielson AT, Sikka SC. Chapter 33 - Environmental Health Policy Regarding Men's Reproductive and Sexual Health. In: Sikka SC, Hellstrom WJG, editors. Bioenvironmental Issues Affecting Men's Reproductive and Sexual Health. Boston: Academic Press; 2018. p. 515-29. https://doi.org/10.1016/B978-0-12801299-4.00033-5 PMid:30152889 PMCid:PMC6431255

24. Rowland DL, McNabney SM, Mann AR. Sexual Function, Obesity, and Weight Loss in Men and Women. Sexual Medicine Reviews, 2017;5(3):323-38. https://doi.org/10.1016/j.sxmr.2017.03.006 PMid:28456610

25. La J, Roberts NH, Yafi FA. Diet and Men's Sexual Health. Sexual Medicine Reviews. 2018;6(1):54-68. https://doi.org/10.1016/j.sxmr.2017.07.004 PMid:28778698

26. Prestage G, Hammoud M, Jin F, Degenhardt L, Bourne A, Maher L. Mental health, drug use and sexual risk behavior among gay and bisexual men. International Journal of Drug Policy. 2018; In Press. https://doi.org/10.1016/j.drugpo.2018.01.020 PMid:29429865

27. Andrasfay T. Reproductive Health-Care Utilization of Young Adults Insured as Dependents. Journal of Adolescent Health, 2018;62(5):570-6. https://doi.org/10.1016/j.jadohealth.2017.11.295 PMid:29415821 PMCid:PMC5930054

28. Sekhavati E, Rahimian-Boogar M, Khodadoost M, Afkari R. Explaining Relation between Self-controlling and Child Parenting Styles and Psychological welfare of High School Students. The AYER, 2015;2:406-25. 
29. Corrêa S. From reproductive health to sexual rights achievements and future challenges. Reproductive Health Matters, 1997;5(10):107-16. https://doi.org/10.1016/S0968-8080(97)90091-4

30. World_Health_Organization. WHO multi-country study on women's health and domestic violence against women: summary report of initial results on prevalence, health outcomes and women's responses. 2005.

31. Mondiale B. Healthy development: The World Bank strategy for health, nutrition, and population results. 2007.

32. Mackenbach JP, McKee M. Government, politics and health policy: A quantitative analysis of 30 European countries. Health policy (Amsterdam, Netherlands), 2015;119(10):1298-308. https://doi.org/10.1016/j.healthpol.2015.08.017 PMid:26375240

33. Mosavi SA, Babazadeh R, Najmabadi KM, Shariati M. Assessing Iranian adolescent girls' needs for sexual and reproductive health information. Journal of Adolescent Health, 2014;55(1):107-13. https://doi.org/10.1016/j.jadohealth.2013.11.029 PMid:24560307

34. Hsieh H-F, Shannon SE. Three approaches to qualitative content analysis. Qualitative health research, 2005;15(9):1277-88. https://doi.org/10.1177/1049732305276687 PMid:16204405

35. Yadollahi P, Khalajinia Z, Khormaei F. Cultural differences in Perception of labor pain without considering to painless Technique. J Adv Pharm Edu Res, 2018;8(S2):9-14.

36. Yadollahi P, Taghizdeh Z, Ebadi A. A comprehensive description of delivery pain using a qualitative approach. J Adv Pharm Edu Res, 2018;8(S2):59-63.

37. Khorasani Baghini, F., khosravani, M., Amiri, A. Evaluation of the effect of the provided training in delivery preparation classes on awareness and attitude of pregnant mothers toward delivery type in Razi Hospital of Saravan. Revista Latinoamericana de Hipertension, 2018;13(6):534-537.

38. Baghini FK, Khosravani M, Amiri A. Evaluation of the effect of the provided training in delivery preparation classes on awareness and attitude of pregnant mothers toward delivery type in Razi Hospital of Saravan, Revista Latinoamericana de Hipertensión, 2018;13(6): Available at: http://saber.ucv.ve/ojs/index.php/rev_lh/article/ view/15949

39. Hashemi SB, Amirfakhraei A, Mosallanezhad M, Amiri A. The effect of education on anxiety and self-efficacy in mothers of 1-3-year-old children under cochlear implant surgery, 2018: a randomized controlled clinical trial, Revista Latinoamericana de Hipertensión, 2019;14(1). Available at: http://saber.ucv.ve/ojs/index.php/rev_lh/ article/view/16170

40. Rakhshan M, Rostami K, Setoodegan E, Eslami J. The relationship between leadership style and time management in senior and middle nursing managers, Revista Latinoamericana de Hipertensión, 2018;14(1). Available at: http://saber.ucv.ve/ojs/index.php/rev_lh/article/view/16173

41. Rostami K, Sharif F, Zarshenas L, Ebadi A, Farbood A. Design and Psychometrics of Measurement Tool of Health Needs in Patients with Chronic Back Ache, Revista Latinoamericana de Hipertensión, 2018;13(3). Available at: http://www.revhipertension.com/index_sumario_3_2018.html

42. Bazrafcan L, Amini M. Using CRISIS model for designing master in medical education at Shiraz University of Medical Sciences. Medical teacher, 2019 Jan 16:1. https://doi.org/10.1080/0142159X.2018.1562540 PMid:30736706

43. Bazrafcan L, Kojuri J, Amini M. Using SPICES educational strategy for undergraduate curricular reform at Shiraz Medical School. Medical teacher, 2019 Mar:1. https://doi.org/10.1080/0142159X.2019.1582759 PMid:30922163

44. Bazrafkan L, Najafi Kalyani M. Nursing Students' Experiences of Clinical Education: A Qualitative Study. Investigación y Educación en Enfermería, 2018 Dec;36(3). https://doi.org/10.17533/udea.iee.v36n3a04

45. Jaafari F, Delavari S, Bazrafkan L. Evaluation of the geriatric curriculum implemented at Shiraz University of Medical Sciences, Iran, since 2017: A qualitative study. F1000Research, 2019 Apr 9;8. https://doi.org/10.12688/f1000research.16040.1

46. Eslami J, Baghini FK, Moazamfard M. The Effect of Music on the Stress Severity among the Staff of Surgery Rooms. International Journal of Pharmaceutical Research, 11(2):838-43. Available at: http://ijpronline.com/ViewArticleDetail.aspx?ID=7339

$\diamond \diamond \diamond \diamond \diamond \diamond \diamond$

http://www.ejgm.co.uk 